University of Wollongong

Research Online

Faculty of Engineering - Papers (Archive)

Faculty of Engineering and Information

Sciences

$1-1-2012$

\title{
Effect of annealing on the microstructure, texture and mechanical properties of severely deformed interstitial free steel
}

Sujoy S. Hazra

University of Wollongong, ssh755@uow.edu.au

Azdiar A. Gazder

University of Wollongong, azdiar@uow.edu.au

E V. Pereloma

University of Wollongong, elenap@uow.edu.au

Follow this and additional works at: https://ro.uow.edu.au/engpapers

Part of the Engineering Commons

https://ro.uow.edu.au/engpapers/4584

\section{Recommended Citation}

Hazra, Sujoy S.; Gazder, Azdiar A.; and Pereloma, E V.: Effect of annealing on the microstructure, texture and mechanical properties of severely deformed interstitial free steel 2012, 1817-1822.

https://ro.uow.edu.au/engpapers/4584

Research Online is the open access institutional repository for the University of Wollongong. For further information contact the UOW Library: research-pubs@uow.edu.au 


\title{
Effect of Annealing on the Microstructure, Texture and Mechanical Properties of Severely Deformed Interstitial Free Steel
}

\author{
Sujoy S. Hazra ${ }^{1,2, a}$, Azdiar A. Gazder ${ }^{1, b}$ and Elena V. Pereloma, \\ ${ }^{1}$ School of Mechanical, Materials and Mechatronic Engineering, University of Wollongong, \\ NSW 2522, Australia \\ ${ }^{2} R \& D$ Division, Tata Steel Ltd., Jamshedpur 831 007, Jharkhand, India \\ asujoyshazra@tatasteel.com, bazdiar@uow.edu.au, elenap@uow.edu.au
}

Keywords: equal channel angular pressing (ECAP); cold rolling; recrystallisation; electron backscattering diffraction (EBSD); mechanical properties.

\begin{abstract}
Ti-stabilised interstitial free (IF) steel initially subjected to 8 passes, route $\mathrm{B}_{\mathrm{C}}$ equal channel angular pressing (ECAP) was further cold rolled (CR) at room temperature to $95 \%$ thickness reduction. Both samples were isothermally annealed at $710{ }^{\circ} \mathrm{C}$ following which their microstructures and micro-textures were compared via electron back-scattering diffraction (EBSD). The mechanical properties first obtained by shear punch testing (SPT) were later corroborated by uniaxial tensile tests. In the case of the ECAP material, continuous recrystallisation is followed by abnormal growth at prolonged annealing times with minor increases in high angle boundary (HAGB) fraction. On the other hand, the additionally $\mathrm{CR}$ material shows continuous recrystallisation accompanied by a reduction in the HAGB fraction. After $15 \mathrm{~s}$ annealing, the ECAP and CR samples exhibit a good strength-ductility balance; which corresponds to $\sim 52 \%$ and $\sim 67 \%$ softening, respectively.
\end{abstract}

\section{Introduction}

Ultrafine grained materials produced by severe plastic deformation (SPD) techniques possess high strength but poor ductility [1] and are thermodynamically unstable due to their postdeformation high stored energy [2]. The latter can be utilised to improve the strength-ductility balance through controlled heat treatment. To date, most annealing studies on SPD materials are on face centred cubic materials [3-11] and the variety of reported annealing phenomena (e.g., extended recovery, discontinuous and continuous recrystallisation/coarsening, normal and abnormal grain growth) is the result of the different deformation microstructures imparted by the various SPD processing techniques. In the present study, the softening behaviour during isothermal annealing of severely deformed, body centred cubic IF steel is explored. Furthermore, the evolution of mechanical properties first tracked by SPT was subsequently corroborated by uniaxial tensile tests.

\section{Experimental and Analytical Methods}

Ti-stabilised IF steel (Fe-0.003C-0.15Mn-0.007Si-0.005S-0.01P-0.03Al-0.08Ti-0.001N wt.\%) billets were subjected to room temperature $\operatorname{ECAP}\left(\Phi=90^{\circ}, \Psi=0^{\circ}\right)$ for 8 passes via route $\mathrm{B}_{\mathrm{C}}$ processing. The ECAP billets were then cold rolled (CR) along the extrusion direction for up to 95\% thickness reduction. Further processing details are described in [12]. Vickers microhardness $\left(\mathrm{H}_{\mathrm{V}}\right)$ and microstructure investigations were undertaken on samples cut parallel to the ND-ED plane from the centre of the stable billet/strip and in the middle of the cross-section. Isothermal annealing was performed at $710{ }^{\circ} \mathrm{C}$ for up to $5 \mathrm{~h}$ in a salt bath furnace where a reproducible heating rate of $\sim 150( \pm 10){ }^{\circ} \mathrm{C} . \mathrm{s}^{-1}$ was established prior to isothermal holding $\left( \pm 2{ }^{\circ} \mathrm{C}\right)$ following which the samples were water quenched. Softening behaviour was characterised by recording $\mathrm{H}_{\mathrm{V}}$ at ten random spots on $1 \mu \mathrm{m}$ diamond suspension polished surfaces using a $500 \mathrm{~g}$ load applied for $12 \mathrm{~s}$. After room temperature electropolishing of sample surfaces with $95 \%$ acetic acid and $5 \%$ perchloric acid 
electrolyte for $12 \mathrm{~s}$ at $30 \mathrm{~V}$, two EBSD maps for each condition were collected on a JEOL JSM7001F FEG-SEM using the Oxford Instruments Corona Fast Acquisition software. Step sizes between $0.025-1 \mu \mathrm{m}$ were chosen such that they represent $<20 \%$ of the average subgrain size for a particular condition. Post-processing of the maps was undertaken using HKL-Channel 5 where the angular resolution limit was set constant at $2^{\circ}$. For micro-texture, orientation distribution function (ODF) sections were calculated using Bunge's notation after exporting EBSD data to MTex [13]. Grains (D) surrounded solely by HAGBs $\left(\theta \geq 15^{\circ}\right)$ and subgrains (d) bounded either by low angle boundaries (LAGBs, $2^{\circ} \leq \theta<15^{\circ}$ ) or partially by HAGBs are represented by equivalent circle diameters. A minimum of two SPT tests per condition was conducted on $\sim 0.8 \mathrm{~mm}$ thick samples on a die-set comprising a $\varnothing 3.01 \mathrm{~mm}$ flat-head punch and $\varnothing 3.018 \mathrm{~mm}$ die. The custom-built rig was fitted to an Instron 5566 operating at a constant cross head speed of $8 \times 10^{-4} \mathrm{~mm} . \mathrm{s}^{-1}$. Compliance removed displacement was measured using a $\pm 2.5 \mathrm{~mm}$ linear variable displacement transducer. Two $15(\mathrm{l}) \times 5(\mathrm{w}) \times 1(\mathrm{t}) \mathrm{mm}^{3}$ flat specimens were tensile tested at room temperature on a servo-hydraulic Instron 1340 at a nominal strain rate of $8 \times 10^{-4} \mathrm{~s}^{-1}$ for selected conditions. In this case, displacement was measured by a video extensometer operating at 33 frames per second.

\section{Results and Discussion}

As-deformed conditions: As shown in Fig. 1(a), the ECAP microstructure consists mostly of slightly elongated (aspect ratio, $\left.\lambda_{d}=2.2-2.6\right)$ subgrains $\left(d_{\text {avg }}=0.44 \mu \mathrm{m}\right)$ and grains $\left(D_{\text {avg }}=0.70\right.$ $\mu \mathrm{m})$ aligned close to the macroscopic shear direction at $\sim 30-40^{\circ}$ to the ED along with a few areas of equiaxed morphology. This condition corresponds to a high total dislocation density $\left(\rho \sim 1.6 \times 10^{15}\right.$ $\left.\mathrm{m}^{-2}\right)$ [14]), non-uniform localised clustering of LAGBs, a high fraction of HAGBs $\left(f_{\mathrm{HAGB}}=63( \pm 2)\right.$ $\%)$ and an average misorientation $\left(\theta_{\text {avg }}\right)$ of $\sim 27^{\circ}$. After ECAP, the major texture components are located near $\mathrm{D}_{1 \theta}$ and $\mathrm{E}_{\theta} / \overline{\mathrm{E}}_{\theta}$ along the $\langle 111\rangle_{\theta}$ fibre and near $\overline{\mathrm{J}}_{\theta}$ along the $\{110\}_{\theta}$ fibre [12]. When the ideal texture components are overlaid on the boundary map with a $20^{\circ}$ tolerance angle (Fig. 1(a)), preferential clustering of orientation components is absent as their spatial distribution remains inhomogeneous [15]. After 95\% CR, the EBSD map in Fig. 1(b) depicts a ribbon-like substructure morphology aligned parallel to the RD. In a few areas, micro-shear bands inclined at $\sim 30-35^{\circ}$ to the rolling plane were observed and is characteristic of inhomogeneous deformation via highly localised plastic flow [12]. Since a few ribbon grains extend up to $10 \mu \mathrm{m}$ along the $\mathrm{RD}$, considerably larger aspect ratios $\left(\lambda_{\text {avg }}\right) \sim 4( \pm 2)$ were recorded along with a small number of $\sim 0.1-0.2 \mu \mathrm{m}$ (sub)grains with $\lambda_{\text {avg }} \sim 1.5-2$. The large (sub)grains appear to be inherited from prior ECAP processing. After 95\% CR, the crystallographic texture evolved from that of negative simple shear after ECAP to typical bcc rolling components and can be described by: (i) a sharp $\alpha(\langle 110\rangle \| \mathrm{RD}$ ) and, (ii) a relatively weaker $\gamma(\langle 111\rangle \| \mathrm{ND})$ fibre [12]. On the $\alpha$-fibre, the highest intensities are found near (113) $[1 \overline{10}]$ along with a considerable spread towards the rotated cube orientation $(\{001\}\langle 110\rangle)$ and intermediate intensities for $(112)[1 \overline{1} 0]$. When a tolerance criterion of $15^{\circ}$ is imposed, $\sim 70 \%$ of the map (see Fig. 1(c)) comprises the four main orientations of the $\alpha$ and $\gamma$-fibres; with a greater tendency of orientation clustering amongst the $\alpha$-fibre components.

Coarsening behavior during annealing: When the hardness -based fraction softened [15] is plotted against annealing time (Fig. 2), the 95\% CR samples soften more than the ECAP samples irrespective of holding time due to the higher stored energy after additional CR. 


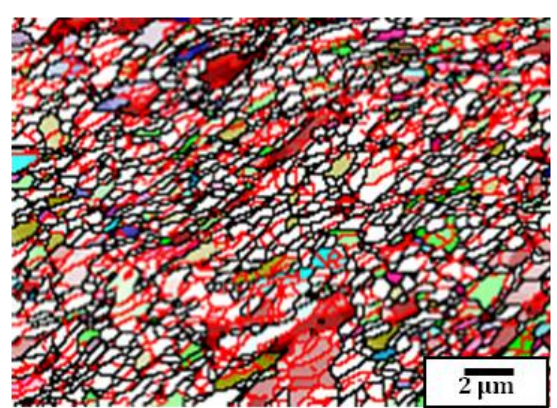

(a)
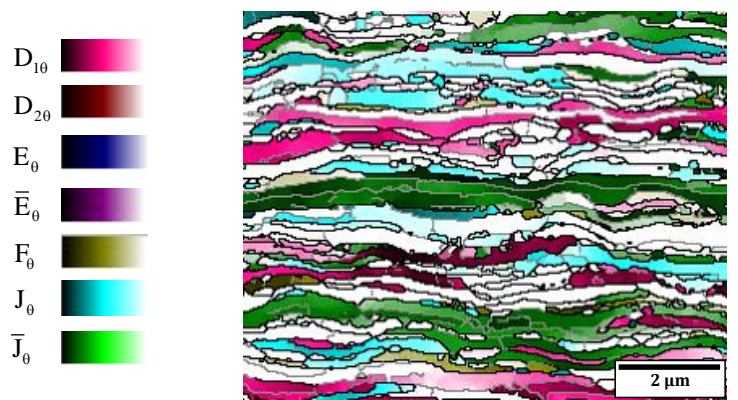

(b)
(001)[1 $1 \overline{1} 0]$

(112)[1 $1 \overline{1} 0]$

$(111)[1 \overline{1} 0]$

(111)[1리]

Fig. 1: Representative grain boundary maps of IF steel after (a) ECAP, overlaid with ideal negative simple shear texture components and (b) $95 \% \mathrm{CR}$, overlaid with ideal rolling texture components. Red $($ grey $)=$ LAGBs, black $=$ HAGBs .

Microstructure evolution during annealing and changes in its associated parameters are illustrated in Figs. 3 and 4, respectively. Annealing the ECAP material at $710{ }^{\circ} \mathrm{C}$ for up to $180 \mathrm{~s}$ results in uniform coarsening accompanied by increases in $\mathrm{d}_{\mathrm{avg}}=3.5 \mu \mathrm{m}, \mathrm{f}_{\mathrm{HAGB}}=71 \%$ and $\theta_{\text {avg }}=$ $32^{\circ}$. After $300 \mathrm{~s}$ and for up to $1 \mathrm{~h}$, discontinuous coarsening produces $\sim 100-150 \mu \mathrm{m}$ abnormally grown grains and $\sim 4.5 \mu \mathrm{m}$ uniformly coarsened matrix grains (Fig. 3(c)). Compared to $180 \mathrm{~s}$, no further changes in $\lambda_{\text {avg }}, \mathrm{f}_{\mathrm{HAGB}}$ and $\theta_{\text {avg }}$ were recorded after $1 \mathrm{~h}$.

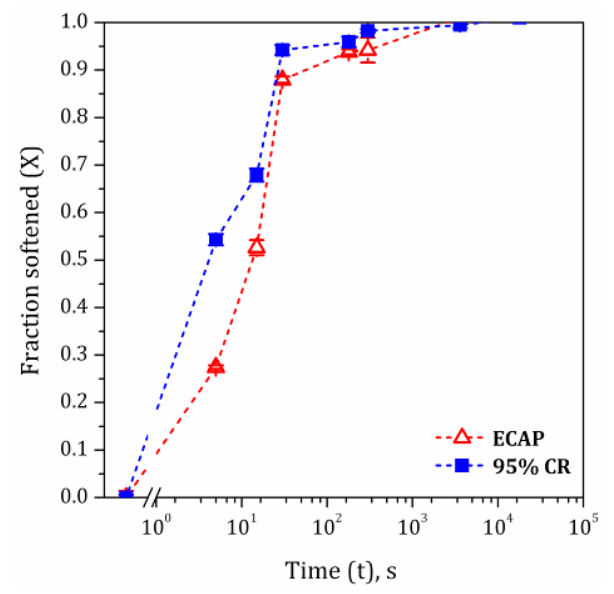

Fig. 2: Fraction softened versus annealing time at $710{ }^{\circ} \mathrm{C}$.

In 95\% CR, annealing leads to a gradual and uniform collapse of the lamellar boundary structure and a subsequent evolution of equiaxed (sub)grains occurs. Annealing at $710{ }^{\circ} \mathrm{C}$ for up to $300 \mathrm{~s}$ results in substantial increases to $\mathrm{d}_{\mathrm{avg}} \sim 6 \mu \mathrm{m}$ and decreases in $\mathrm{f}_{\mathrm{HAGB}} \sim 55 \%$ and $\theta_{\text {avg }} \sim 20^{\circ}$. Beyond $300 \mathrm{~s}$, only minor changes were noted in the various microstructural parameters (Fig. 4).

In the normalised subgrain size frequency versus $\log \left(\mathrm{d} / \mathrm{d}_{\text {avg }}\right)$ plots (Fig. 5), the invariant nature of the subgrain size distributions is clearly evident indicating continuous coarsening; while their extended tails represent discontinuous coarsening. Similar observations on the general form of the subgrain size distribution were made on annealed ECAP Al alloys [8, 10]. Apart from sluggish growth kinetics beyond $30 \mathrm{~s}$ for the ECAP material, coarsening via recovery-like processes is further evidenced by the preservation and sharpening of the deformation texture $[15,16]$. Due to the high fraction of strain-induced HAGBs $(\sim 63 \%)$ after ECAP, annealing results in a homogeneous softening (or continuous recrystallisation) without a discernible nucleation and growth sequence [17]. After $300 \mathrm{~s}$ annealing the ECAP material comprises a location dependent $\sim 20 \%$ area fraction of abnormally large grains $\left(\mathrm{d}_{\max } / \mathrm{d}_{\mathrm{avg}} \sim 28\right)$ primarily surrounded by HAGBs and a uniformly coarsened matrix with LAGB clusters. Here, the heterogeneous dispersion of abnormal grains was also confirmed by EBSD over a scan area of $\sim 7 \times 0.2 \mathrm{~mm}^{2}$. 


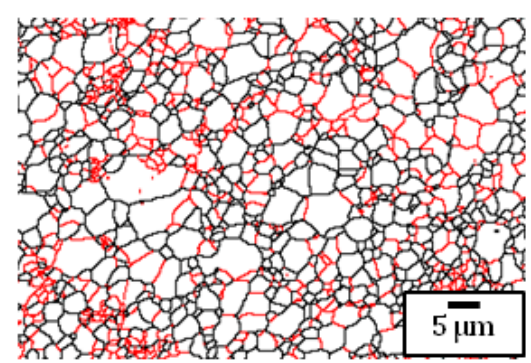

(a)

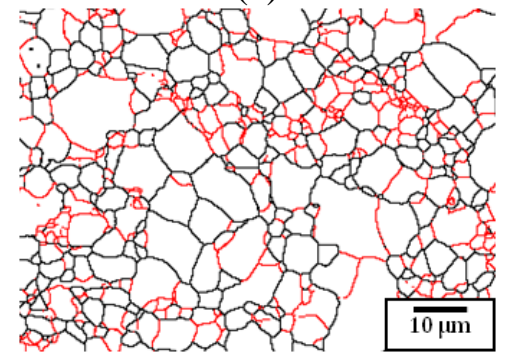

(d)

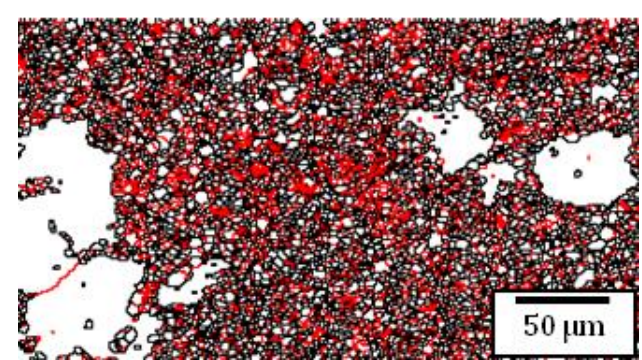

(b)

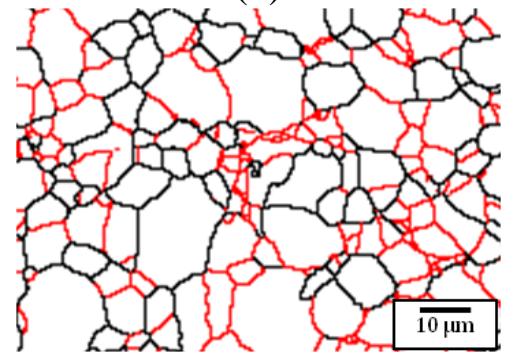

(e)

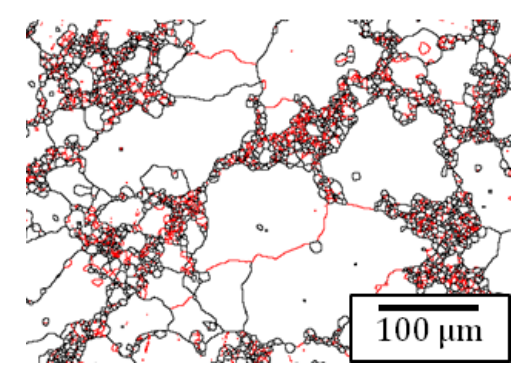

(c)

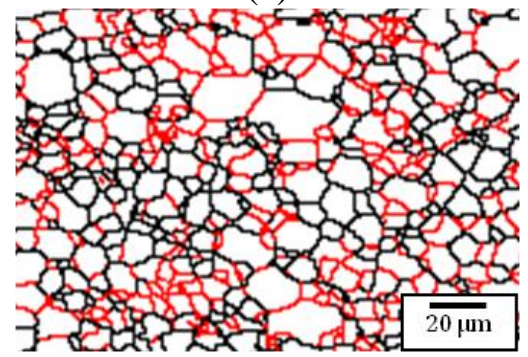

(f)

Fig. 3: Representative grain boundary maps of IF steel after (a-c) ECAP and (d-f) 95\% CR, annealed at $710{ }^{\circ} \mathrm{C}$ for (a, d) $30 \mathrm{~s},(\mathrm{~b}, \mathrm{e}) 300 \mathrm{~s}$ and (c, f) $1 \mathrm{hr}$.

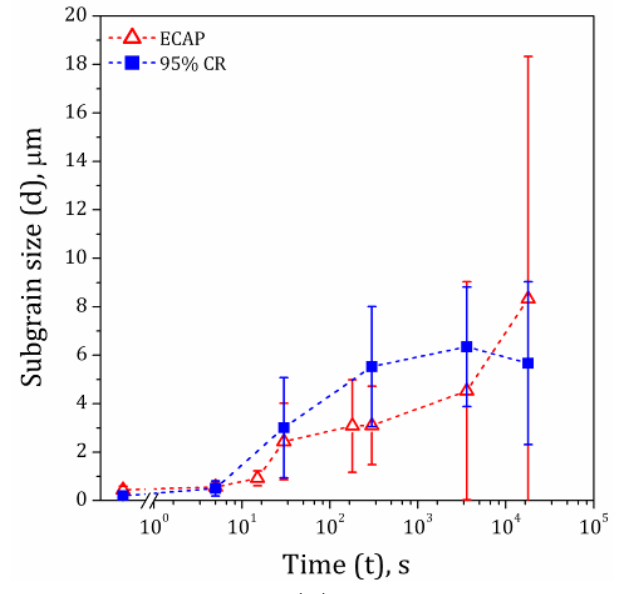

(a)

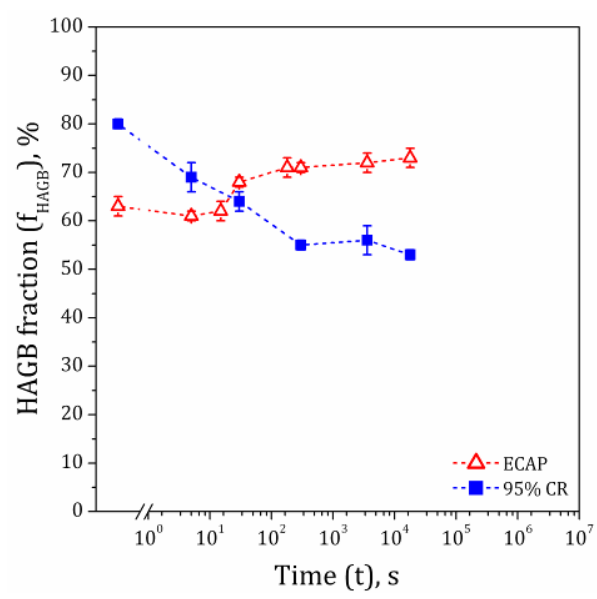

(b)

Fig. 4: Evolution of (a) subgrain size and (b) HAGB fraction during annealing at $710{ }^{\circ} \mathrm{C}$.

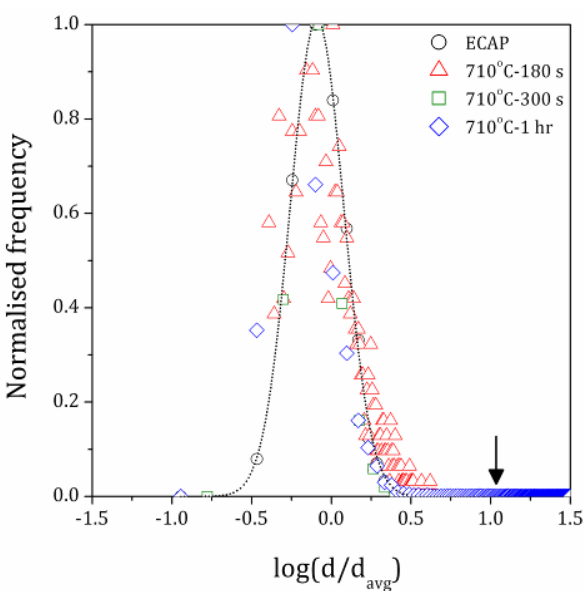

(a)

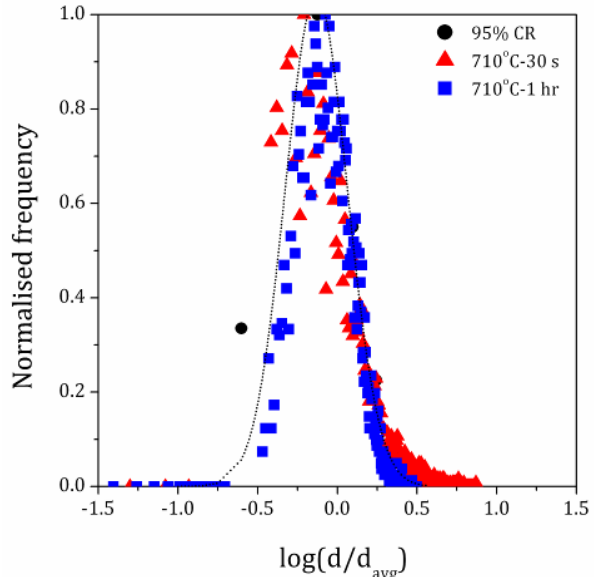

(b)

Fig. 5: Evolution of normalised subgrain size distribution during annealing at $710{ }^{\circ} \mathrm{C}$ of (a) ECAP and (b) $95 \% \mathrm{CR}$. 
After $1 \mathrm{hr} \sim 80 \%$ of the map area is covered by the abnormally large grains $\left(\mathrm{d}_{\max } / \mathrm{d}_{\text {avg }} \sim 38\right)$ as they consumed a significant fraction of surrounding matrix grains. It is noteworthy that orientation preference could not be ascertained: (i) between LAGB clusters within the uniformly coarsened matrix or, (ii) between the abnormally large gains and the neighbouring matrix. Consequently, the formation of these abnormally large grains can be attributed to local growth advantages dictated by the presence of low mobility LAGBs in their neighbourhood. Boundary pinning effects on the formation of these abnormal grains can be ruled out as the volume fraction $\left(\sim 10^{-4}\right)$ of $\mathrm{TiC}$ precipitates in clean interstitial free steels is insignificant to cause Zener pinning [14, 18].

Interestingly, although the annealed 95\% CR microstructure coarsens homogeneously up to the final stages of softening, the LAGB fraction also concurrently increases. This can be attributed to texture clustering and/or orientation pinning effects $[4,19]$. When deformation textures are strong and spread over a narrow orientation range, as in the case of $95 \% \mathrm{CR}$, the chances of similarly oriented (sub)grains becoming neighbours is increased when coarsening via boundary migration occurs during annealing. Under such circumstances, local clusters of LAGBs with reduced mobility form progressively via orientation pinning (or impingement) and results in an increasing area fraction of LAGBs with extended annealing times.

Characterisation of mechanical properties: Subsequent to determination of shear stress and normalised displacement from SPT [15], uniaxial tensile behaviour was characterised as shown in Fig. 6. Linear correlations for estimating yield strength, tensile strength and total elongations were derived over a wider range of ultrafine (sub)grain sizes for the present IF steel $[15,16]$. It is evident that subgrain/grain refinement via SPD results in increased strengths and reduced ductility while microstructural coarsening during annealing is marked by a loss in strength and return of ductility.

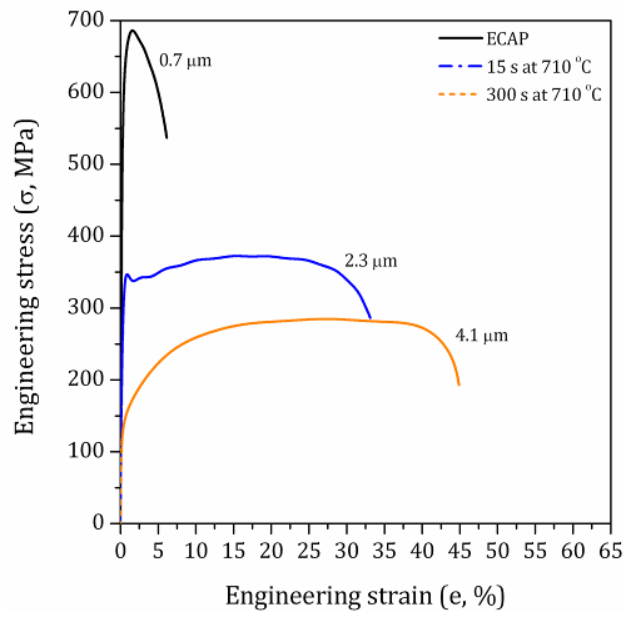

(a)

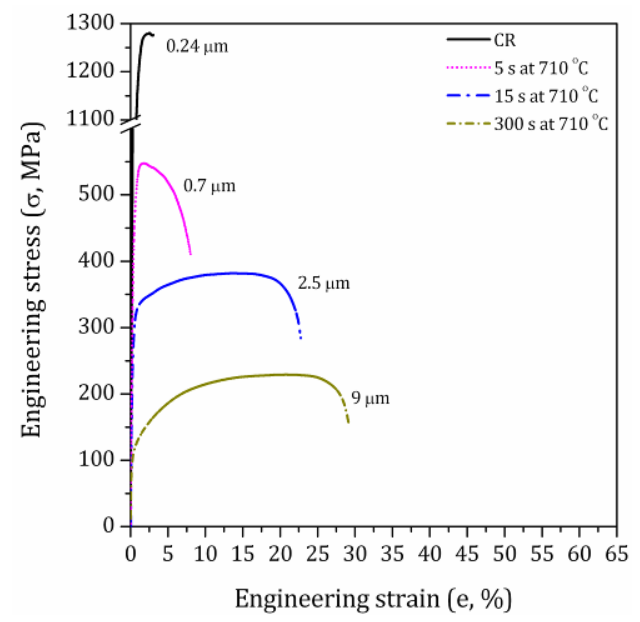

(b)

Fig. 6: Tensile curves after annealing at $710{ }^{\circ} \mathrm{C}$ of (a) ECAP and (b) $95 \% \mathrm{CR}$. Note the values of $\mathrm{D}_{\text {avg. }}$.

The evolution of tensile behaviour upon annealing is grain-size dependent and changes from that of early necking in the as-deformed conditions, to Lüders banding and finally to continuous yielding and work hardening upon annealing. Similar findings on annealing of 8 passes, route $\mathrm{B}_{\mathrm{C}}$ ECAP Al [20] and ARB of Ti-IF steel and commercially pure Al [21] are indicative of the scarcity of mobile dislocations in these clean ultrafine grain microstructures [22]. In terms of achieving a strength-ductility balance, irrespective of ECAP or $95 \% \mathrm{CR}$, annealing for $15 \mathrm{~s}$ at $710{ }^{\circ} \mathrm{C}$ resulted in a yield strength $\sim 300-330 \mathrm{MPa}$, ultimate tensile strength $\sim 370-380 \mathrm{MPa}$, uniform elongation $\sim 15-$ $18 \%$ and total elongation $\sim 23-33 \%$ when a grain size of $\sim 2.5 \mu \mathrm{m}$ is reached. 


\section{Conclusions}

1. The ECAP microstructure with $\sim 63 \%$ HAGBs underwent coarsening via continuous recrystallisation followed by abnormal growth. On the other hand, the $95 \% \mathrm{CR}$ microstructure with $\sim 80 \%$ HAGBs coarsened homogeneously following normal growth via continuous recrystallisation.

2. Abnormal growth occurred in annealed ECAP microstructures during the final stages of softening via local growth advantages dictated by the presence of low mobility LAGBs in their neighbourhood. The progressive decrease of HAGBs to $~ 50 \%$ during annealing of $95 \% \mathrm{CR}$ samples is the result of texture clustering and orientation pinning during grain growth.

3. Grain size dependent evolution of uniaxial tensile behaviour was noted such that the optimum strength-ductility balance is obtained after $15 \mathrm{~s}$ annealing at $710^{\circ} \mathrm{C}$.

\section{Acknowledgements}

SSH is grateful to Tata Steel Ltd., India for study leave.

\section{References}

[1] R. Z. Valiev, I. V. Alexandrov, Y. T. Zhu, T. C. Lowe, Journal of Materials Research 17 (2002) 5-8.

[2] J. H. Driver, Scripta Materialia 51 (2004) 819-823.

[3] W. Q. Cao, A. Godfrey, N. Hansen, Q. Liu, Metallurgical and Materials Transactions A 40 (2009) 204-214.

[4] G. H. Zahid, Y. Huang, P. B. Prangnell, Acta Materialia 57 (2009) 3509-3521.

[5] H. Jazaeri, F. J. Humphreys, Acta Materialia 52 (2004) 3251-3262.

[6] H. W. Zhang, X. Huang, R. Pippan, N. Hansen, Acta Materialia 58 (2010) 1698-1707.

[7] M. Ferry, N. E. Hamilton, F. J. Humphreys, Acta Materialia 53 (2005) 1097-1109.

[8] C. Y. Yu, P. L. Sun, P. W. Kao, C. P. Chang, Materials Science and Engineering A 366 (2004) 310-317.

[9] X. Molodova, G. Gottstein, M. Winning, R. J. Hellmig, Materials Science and Engineering: A 460-461 (2007) 204-213.

[10] D. G. Morris, M. A. Muñoz-Morris, Acta Materialia 50 (2002) 4047-4060.

[11] O. Engler, M.-Y. Huh, Materials Science and Engineering A 271 (1999) 371-381.

[12] S. S. Hazra, A. A. Gazder, A. Carman, E. V. Pereloma, Metallurgical and Materials Transactions A doi: 10.1007/s11661-010-0535-5 (2010).

[13] R. Hielscher, H. Schaeben, Journal of Applied Crystallography 41 (2008) 1024-1037.

[14] S. S. Hazra, A. A. Gazder, E. V. Pereloma, Materials Science and Engineering: A 524 (2009) 158-167.

[15] S. S. Hazra, E. V. Pereloma, A. A. Gazder, Acta Materialia (2010) (Under Review).

[16] A. A. Gazder, S. S. Hazra, E. V. Pereloma, Material Science and Engineering A (2010) (Under Review).

[17] F. J. Humphreys, M. Hatherly, Recrystallization and related annealing phenomena, Pergamon Press, Oxford, 2004.

[18] J.-Y. Choi, B.-S. Seong, S. C. Baik, H. C. Lee, ISIJ International 42 (2002) 889-893.

[19] D. Juul Jensen, Acta Metallurgica et Materialia 43 (1995) 4117-4129.

[20] C. Y. Yu, P. W. Kao, C. P. Chang, Acta Materialia 53 (2005) 4019-4028.

[21] N. Tsuji, Y. Ito, Y. Saito, Y. Minamino, Scripta Materialia 47 (2002) 893-899.

[22] J. W. Wyrzykowski, M. W. Grabski, Materials Science and Engineering 56 (1982) 197-200. 